\title{
Predictors of Remission in Acute and Continuation Treatment of Depressive Disorders
}

\author{
Ha-Yeon Kim, Hee-Joon Lee, Min Jhon, Ju-Wan Kim, Hee-Ju Kang, Ju-Yeon Lee, Sung-Wan Kim, Il-Seon Shin, \\ Jae-Min Kim \\ Department of Psychiatry, Chonnam National University Medical School, Gwangju, Korea
}

\begin{abstract}
Objective: To identify factors predicting remission of depression during acute (12 weeks) and continuation treatment (12 months) using a 1-year, naturalistic prospective study design.

Methods: Patients with depressive disorders were recruited from Chonnam National University Hospital in South Korea from March 2012 to April 2017. At baseline, 1,262 patients received outpatient therapy, and sociodemographic and clinical data were obtained. Clinical visits took place every 3 weeks during the acute treatment phase (at 3, 6, 9, and 12 weeks; $n=1,246$ ), and every 3 months during the continuation treatment phase (at 6, 9, and 12 months; $\mathrm{n}=1$,015). Remission was defined as a Hamilton Depression Rating Scale score $\leq 7$.

Results: The remission rate was $43.3 \%$ at 12 weeks and $70.4 \%$ at 12 months. In multivariate analyses, remission during the acute treatment phase was more likely in patients with a shorter-duration present episode, higher functioning, and good social support. Remission during the continuation treatment phase was more likely in patients with fewer previous depressive episodes and/or a lower baseline stress score.

Conclusion: Factors predicting depressive disorder remission may differ between the acute and continuation treatment phases.
\end{abstract}

KEY WORDS: Depression; Remission; Pharmacotherapy; Prediction.

\section{INTRODUCTION}

Major depressive disorder (MDD) is a common disorder and a major contributor to the global burden of disease $[1,2]$. However, most patients with MDD (about $60 \%$ ) do not achieve remission after the acute treatment phase (usually 12 weeks), even in antidepressant trials with optimal conditions [3]. Moreover, a meta-analysis found that after continuous antidepressant treatment for at least 6 months, the mean remission rate of depressive disorder was $51 \%$ in primary care and $62 \%$ in controlled studies [4]. Antidepressant trials last for several weeks, during which time patients may experience mental suffering, disability, economic costs, and possibly even death by suicide [5]. Many clinicians agree that, in addition to

Received: July 9, 2020 / Accepted: July 21, 2020

Address for correspondence: Jae-Mim Kim

Department of Psychiatry, Chonnam National University Medical School, 160 Baekseo-ro, Dong-gu, Gwangju 61469, Korea

E-mail: jmkim@chonnam.ac.kr

ORCID: https://orcid.org/0000-0001-7409-6306 the diagnosis, other information is required for successful depression treatment [6]. Identifying predictors of outcome is important and could enhance clinical decisionmaking, thus ultimately improving patient care and outcomes. Socioeconomic and clinical factors represent the typical predictors of depressive disorder outcomes [7]. Being married, having good social support, and low levels of baseline depressive symptoms were associated with more favorable outcomes in most studies [8-10]. The evidence that baseline disease severity predicts the response to antidepressants is especially convincing $[9,11,12]$. Comorbid anxiety and pain were related to worse antidepressant treatment outcomes $[13,14]$. However, previous investigations have generally focused on the acute treatment period, and some were concerned with the response to treatment rather than remission $[7,15,16]$. In this study, we build on previous investigations focusing on general predictors of depressive disorder outcomes by exploring a wider range of factors predicting treatment outcomes not only in the acute treatment phase, but also

(ㄷ) This is an Open-Access article distributed under the terms of the Creative Commons Attribution Non-Commercial License (http://creativecommons.org/licenses/by-nc/4.0) which permits unrestricted non-commercial use, distribution, and reproduction in any medium, provided the original work is properly cited. 
in the continuation treatment phase.

\section{METHODS}

\section{Study Outline}

This study analyzed data from the MAKE BETTER (MAKE Biomarker discovery for Enhancing anTidepressant Treatment Effect and Response) study. A design paper has been published for this 1-year prospective clinical study [17], which was registered at cris.nih.go.kr (identifier: KCT0001332). The study, which began in 2012, investigated treatment responses in a real-world setting and included a large patient sample. Decisions pertaining to antidepressant type, dose, and regimen were made in a naturalistic environment. Symptom severity was assessed at baseline, at 1 and 2 weeks, and then every 3 weeks during the acute treatment phase $(3,6,9$, and 12 weeks), and every 3 months during the continuation treatment phase (6, 9 , and 12 months). Sociodemographic, clinical, and treatment-related predictors of remission were obtained using a structured case report form (CRF). We uploaded the CRF data to the MAKE BETTER study website (http://icreat.nih. go.kr/icreat/webapps/com/hismainweb/jsp/cdc_n2.live) within 3 days. This study was approved by the Chonnam National University Hospital Institutional Review Board (CNUH 2012-014).

\section{Participants}

Patients with depressive disorders were recruited between March 2012 and April 2017 from among those who had visited the outpatient psychiatric department of Chonnam National University Hospital. All cases in this study were of a new episode of depression, regardless of whether the patient had first-onset or recurrent depression. The investigators evaluated the depressive episodes using the Mini-International Neuropsychiatric Interview [18], and diagnosed patients during a structured diagnostic psychiatric interview based on the Diagnostic and Statistical Manual of Mental Disorders, Fourth Edition (DSM-IV) criteria (American Psychological Association, APA; 1994). There was no economic compensation for study participation, and psychiatrists conducted treatment in line with routine clinical care settings. To reflect the actual clinical situation in Korea, broad inclusion criteria and minimal exclusion criteria were applied. The inclusion criteria were i) aged older than 7 years; ii) diagnosed with MDD, dysthymic disorder, or depressive disorder not otherwise specified (NOS); iii) Hamilton Depression Rating Scale (HAMD) [19] score $\geq 14$; and iv) able to understand the objectives of the study and complete the questionnaires. The exclusion criteria were as follows: i) unstable medical condition or severe physical illness; ii) current or lifetime DSM-IV diagnosis of bipolar disorder, schizophrenia, schizoaffective disorder, schizophreniform disorder, psychotic disorder NOS, or other psychotic disorder; iii) history of organic psychosis, epilepsy, or seizures; iv) history of anticonvulsant treatment; v) hospitalization for any psychiatric diagnosis apart from depressive disorder (e.g., alcohol/drug dependence); vi) electroconvulsive therapy received for the current depressive episode; and vii) pregnant or breastfeeding. All participants were asked to read the consent form and provide written informed consent.

\section{Measurements at Baseline}

Sociodemographic characteristics were obtained by a research coordinator using the CRF. The data collected included age, sex, years of formal education, marital status, cohabitation status (living alone or not), religion, occupation (currently employed or not), and income (above or below 2,000 USD per month).

Clinical characteristics were also obtained using the CRF, including age at onset and duration of illness, number of previous depressive episodes, duration of present episode, family history of depression, history of suicide attempts, and number of concurrent physical disorders.

Depressive symptoms were assessed using the HAMD; anxiety symptoms were assessed using the Hospital Anxiety Depression Scale anxiety subscale (HADS-A) [20]; quality of life was assessed using the EuroQol-5D (EQ-5D) [21]; and level of functioning was assessed using the Social and Occupational Functioning Assessment Scale (SOFAS) (APA, 1994).

\section{Treatment}

Before the start of treatment, clinicians reviewed patients' clinical manifestations (e.g., psychotic or anxiety symptoms, severity of illness, physical comorbidities, medications, and history of previous treatments). Antidepressants administered included bupropion, desvenlafaxine, duloxetine, escitalopram, fluoxetine, mirtazapine, paroxetine, sertraline, venlafaxine, and vortioxetine. The starting doses were determined according to patient age, body 
weight, physical comorbidities and other drug use. After the initial treatment had been decided on, changes to the pharmacologic strategy could be made every 3 weeks during the acute treatment phase and every 3 months during the continuation treatment phase, as needed.

At every follow-up visit, a clinician reviewed the effectiveness and tolerability of each patient's pharmacological regimen. In cases of insufficient improvement (reduction in HAMD score of $<30 \%$ from baseline) or intolerable side effects, dose adjustment, switching, augmentation, and combination treatment were considered. The risks and benefits of each strategy were explained, and the clinician offered their opinion taking both the patient's data and treatment guidelines into consideration [22-24]. To improve medication compliance, the patient's preference was prioritized when choosing a treatment strategy [25]. Use of anxiolytics/hypnotics (including alprazolam, bromazepam, clonazepam, clorazepate, diazepam, ethyl loflazepate, flunitrazepam, lorazepam, and zolpidem) was allowed at any time during the study to improve efficacy, relieve associated symptoms, or treat side effects.

\section{Measurements for Outcomes}

Data were collected during two phases: the acute treatment phase (3, 6, 9, and 12 weeks; 3-day allowable window) and the continuation treatment phase $(6,9$, and 12 months; 7-day allowable window). The data for these two phases corresponded to short- and long-term treatment outcomes, respectively. The main outcome measure was the HAMD score: remission was defined as a HAMD score $\leq 7$.

\section{Statistical Analysis}

Remission status was recorded at each evaluation point after baseline. The analysis of outcomes during the 12week acute phase included patients evaluated at least once after baseline. Multiple imputation by chained equations was applied in cases of missing data due to discontinuation after the second (week 3 ) assessment, imputing by age, sex, and baseline scores on HAMD. We defined 12-week remission as remission maintained up to the 12-week assessment point. Regarding the 12-month outcome evaluation, the analysis included patients evaluated at least once between baseline and 12 weeks, and at least once from 6 months onward. Multiple imputation by chained equations was applied in cases of missing data at the 6-, 9-, and 12-month assessment points, imputing by age, sex, and baseline scores on HAMD. Patients were considered to have achieved 12-month remission only when remission was maintained up to the 12-month assessment point. Sociodemographic, clinical, and treatment characteristics were analyzed according to both 12-week and 12-month remission status using $t$ test or $\chi^{2}$ tests, as appropriate. Characteristics significantly associated with remission at the 12-week and 12-month assessment points $(p<0.05)$ were entered into a multiple logistic regression model to identify independent predictors. Statistical analyses were carried out using SPSS 21.0 software (IBM Co., Armonk, NY, USA).

\section{RESULTS}

\section{Characteristics of the Sample}

The patient recruitment process is summarized in Figure 1. Of 1,262 patients evaluated at baseline, 1,246 $(98.7 \%)$ attended the 3-week follow-up 1,226 (97.1\%) attended the 6-week follow-up, 1,180 (93.5\%) attended the 9-week follow-up, and 1,104 (87.5\%) attended the 12-week follow-up. Overall, 1,246 patients attended at least one follow-up visit during the 12-week treatment pe-

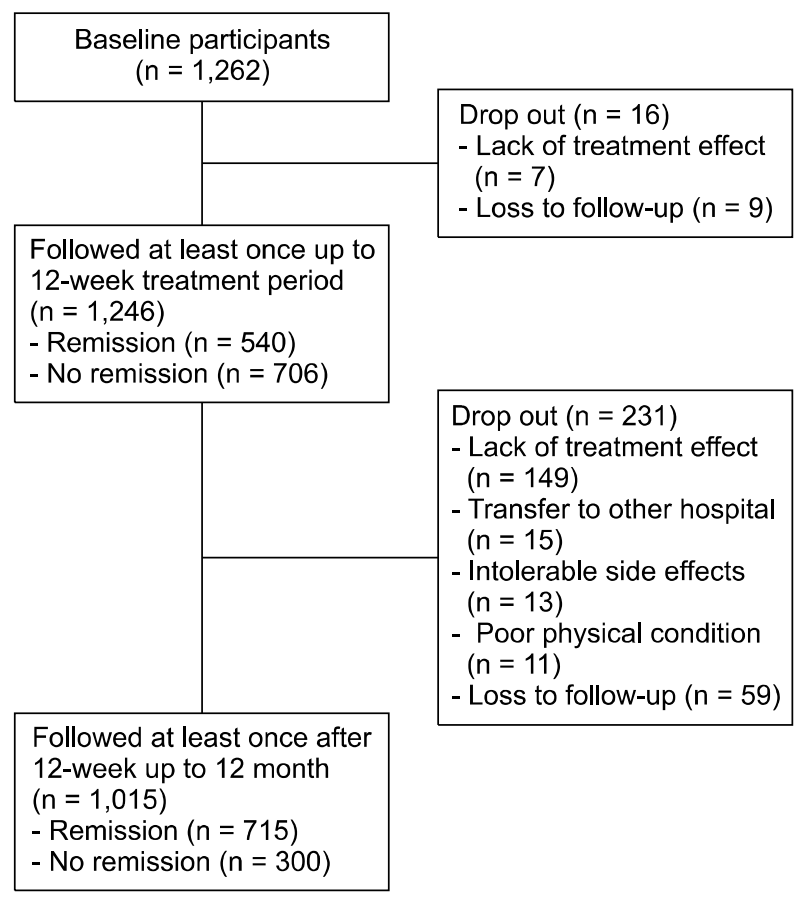

Fig. 1. Recruitment process of study participants. 
riod; those patients comprised the sample analyzed in terms of acute treatment outcomes. There was no statistical difference in any baseline characteristic between the 1,246 patients included in the analysis and the 16 that were excluded (all $p>0.6$ ).

After the acute treatment phase, 963 (76.2\%) patients attended the 6-month follow up, $820(65.0 \%)$ attended the 9-month follow up, and 675 (53.5\%) attended the 12-month follow up. Overall, 1,015 (81.5\%) patients attended at least one follow-up visit during the continuation treatment period; those patients comprised the sample analyzed in terms of continuation treatment outcomes. Attrition at 12 months was significantly associated with unemployed status and higher EQ-5D scores at baseline.

\section{Factors Showing Unadjusted Associations with Remission during the Acute and Continuation Treatment Phases}

The cumulative remission rate at 12 weeks was $43.3 \%$ (540 of 1,262 patients). The baseline sociodemographic and clinical characteristics of the 12-week patient sample are compared by remission status in Table 1. Remission was associated with being married, a shorter-duration present depressive episode, fewer previous depressive episodes, higher age of onset, lower baseline HAMD and HADS scores, and a higher SOFAS score. The cumulative

Table 1 . Baseline characteristics by remission status in patient with depressive disorders at 12 week and at 12 month

\begin{tabular}{|c|c|c|c|c|c|c|c|c|}
\hline \multirow[b]{2}{*}{ Variable } & \multicolumn{4}{|c|}{ At 12 week $(n=1,246)$} & \multicolumn{4}{|c|}{ At 12 month $(n=1,015)$} \\
\hline & $\begin{array}{l}\text { No remission } \\
\quad(n=706)\end{array}$ & $\begin{array}{l}\text { Remission } \\
(\mathrm{n}=540)\end{array}$ & $\begin{array}{c}\text { Statistical } \\
\text { coefficients }\end{array}$ & $p$ value & $\begin{array}{l}\text { No remission } \\
\quad(\mathrm{n}=300)\end{array}$ & $\begin{array}{l}\text { Remission } \\
(\mathrm{n}=715)\end{array}$ & $\begin{array}{c}\text { Statistical } \\
\text { coefficients }\end{array}$ & $p$ value \\
\hline \multicolumn{9}{|l|}{ Socio-demographic characteristics } \\
\hline Age (yr) & $55.5 \pm 15.9$ & $58.4 \pm 14.0$ & $\mathrm{t}=-3.447$ & $0.001^{\dagger}$ & $55.8 \pm 16.2$ & $57.3 \pm 14.5$ & $t=-1.403$ & 0.161 \\
\hline Sex, female & $495(70.5)$ & $365(67.5)$ & $\chi^{2}=1.329$ & 0.249 & $205(68.3)$ & $499(69.8)$ & $\chi^{2}=0.211$ & 0.646 \\
\hline Education (yr) & $9.2 \pm 4.7$ & $9.1 \pm 4.9$ & $\mathrm{t}=+0.136$ & 0.892 & $9.4 \pm 4.6$ & $9.0 \pm 4.9$ & $\mathrm{t}=+1.386$ & 0.169 \\
\hline Marital status, unmarried & $234(33.3)$ & $148(27.4)$ & $\chi^{2}=5.127$ & $0.024 *$ & $100(33.3)$ & $204(28.5)$ & $\chi^{2}=2.323$ & 0.128 \\
\hline Living alone & $107(15.2)$ & $79(14.6)$ & $\chi^{2}=0.098$ & 0.754 & $49(16.3)$ & $100(14.0)$ & $\chi^{2}=0.930$ & 0.335 \\
\hline Religious affiliation & $316(45.0)$ & $228(42.1)$ & $\chi^{2}=1.023$ & 0.312 & $134(44.7)$ & $309(43.2)$ & $\chi^{2}=0.181$ & 0.671 \\
\hline Unemployed status & $217(30.9)$ & $147(27.2)$ & $\chi^{2}=2.064$ & 0.151 & $89(29.7)$ & $190(26.6)$ & $\chi^{2}=1.014$ & 0.314 \\
\hline Monthly income, $<2,000$ USD & $433(61.7)$ & $306(56.6)$ & $\chi^{2}=3.321$ & 0.068 & $190(63.3)$ & $409(57.2)$ & $\chi^{2}=3.284$ & 0.070 \\
\hline \multicolumn{9}{|l|}{ Clinical characteristics } \\
\hline Major depressive disorder & $601(85.6)$ & $460(85.0)$ & $\chi^{2}=0.084$ & 0.772 & $260(86.7)$ & $612(85.6)$ & $\chi^{2}=0.201$ & 0.654 \\
\hline Atypical feature & $47(6.7)$ & $35(6.5)$ & $\chi^{2}=0.025$ & 0.874 & $18(6.0)$ & $47(6.6)$ & $\chi^{2}=0.116$ & 0.733 \\
\hline Melancholic feature & $107(15.2)$ & $77(14.2)$ & $\chi^{2}=0.247$ & 0.619 & $50(16.7)$ & $109(15.2)$ & $\chi^{2}=0.323$ & 0.570 \\
\hline Age at onset (yr) & $50.4 \pm 17.4$ & $53.8 \pm 15.8$ & $t=-3.698$ & $<0.001^{\dagger}$ & $50.4 \pm 17.9$ & $52.5 \pm 16.2$ & $t=-1.793$ & 0.074 \\
\hline Duration of illness (yr) & $5.1 \pm 9.0$ & $4.6 \pm 8.5$ & $t=+1.149$ & 0.251 & $5.4 \pm 8.9$ & $4.8 \pm 8.7$ & $t=+1.041$ & 0.298 \\
\hline Recurrent depression & $371(52.8)$ & $273(50.5)$ & $\chi^{2}=0.697$ & 0.404 & $163(54.3)$ & $362(50.6)$ & $\chi^{2}=0.161$ & 0.281 \\
\hline Number of depressive episodes & $1.2 \pm 1.6$ & $1.0 \pm 1.4$ & $t=+2.118$ & $0.034^{*}$ & $1.4 \pm 1.8$ & $1.0 \pm 1.3$ & $t=+3.626$ & $<0.001^{\dagger}$ \\
\hline Duration of present episode (mo) & $8.2 \pm 11.9$ & $6.4 \pm 8.1$ & $t=+3.134$ & $0.002^{\dagger}$ & $8.4 \pm 12.3$ & $7.2 \pm 9.5$ & $t=+1.477$ & 0.140 \\
\hline Family history of depression & $99(14.1)$ & $83(15.3)$ & $\chi^{2}=0.376$ & 0.540 & $40(13.3)$ & $104(14.5)$ & $\chi^{2}=0.255$ & 0.614 \\
\hline History of suicide attempt & $75(10.7)$ & $44(8.1)$ & $\chi^{2}=2.296$ & 0.130 & $36(12.0)$ & $59(8.3)$ & $\chi^{2}=3.500$ & 0.061 \\
\hline Number of physical disorders & $1.6 \pm 1.3$ & $1.7 \pm 1.2$ & $\mathrm{t}=-1.298$ & 0.195 & $1.6 \pm 1.3$ & $1.6 \pm 1.3$ & $\mathrm{t}=-0.249$ & 0.803 \\
\hline \multicolumn{9}{|l|}{ Assessment scales (score) } \\
\hline Hamilton Depression Rating Scale & $21.1 \pm 4.3$ & $20.4 \pm 4.2$ & $\mathrm{t}=+2.800$ & $0.005^{\dagger}$ & $20.9 \pm 4.4$ & $20.7 \pm 4.2$ & $\mathrm{t}=+0.712$ & 0.477 \\
\hline $\begin{array}{l}\text { Hospital Anxiety \& Depression } \\
\text { Scale-anxiety subscale }\end{array}$ & $12.1 \pm 4.0$ & $11.3 \pm 4.1$ & $\mathrm{t}=+3.170$ & $0.002^{\dagger}$ & $12.1 \pm 4.0$ & $11.6 \pm 4.0$ & $\mathrm{t}=+2.083$ & $0.038^{*}$ \\
\hline EuroQol-5D & $8.9 \pm 1.6$ & $8.8 \pm 1.5$ & $t=+1.463$ & 0.144 & $8.9 \pm 1.5$ & $8.8 \pm 1.5$ & $t=+1.467$ & 0.140 \\
\hline $\begin{array}{l}\text { Social and Occupational } \\
\text { Functional Assessment Scale }\end{array}$ & $54.9 \pm 7.7$ & $57.1 \pm 7.2$ & $t=-5.192$ & $<0.001^{\dagger}$ & $55.4 \pm 7.2$ & $56.3 \pm 7.4$ & $t=-1.642$ & 0.101 \\
\hline Number of stressful life events & $2.2 \pm 1.7$ & $1.9 \pm 1.7$ & $t=+2.689$ & $0.007^{\dagger}$ & $2.2 \pm 1.7$ & $2.0 \pm 1.7$ & $t=+1.864$ & 0.063 \\
\hline Perceived Stress Scale & $27.5 \pm 6.5$ & $26.6 \pm 6.4$ & $\mathrm{t}=+2.418$ & $0.016^{*}$ & $28.0 \pm 6.0$ & $26.7 \pm 6.6$ & $t=+2.906$ & $0.004^{\dagger}$ \\
\hline Connor-Davidson Resilience Scale & $41.5 \pm 179$ & $44.9 \pm 17.8$ & $\mathrm{t}=-3.270$ & $0.001^{\dagger}$ & $42.7 \pm 18.1$ & $43.4 \pm 17.6$ & $t=-0.592$ & 0.554 \\
\hline Social Support Deficit & $38.2 \pm 12.1$ & $40.5 \pm 11.5$ & $t=-3.370$ & $0.001^{\dagger}$ & $39.1 \pm 12.1$ & $39.6 \pm 11.6$ & $t=-0.663$ & 0.527 \\
\hline
\end{tabular}

Values are presented as mean \pm standard deviation or number $(\%)$.

${ }^{*} p<0.05,{ }^{\dagger} p<0.01$ by $t$ tests. 
Table 2. Predictors of remission at 12 weeks and 12 months

\begin{tabular}{|c|c|c|c|c|}
\hline \multirow{2}{*}{ Variable } & \multicolumn{2}{|c|}{ At 12 week $(n=1,246)$} & \multicolumn{2}{|c|}{ At 12 month $(\mathrm{n}=1,015)$} \\
\hline & OR $(95 \% \mathrm{Cl})$ & $p$ value & OR $(95 \% \mathrm{Cl})$ & $p$ value \\
\hline Age, higher & $1.01(0.99-1.03)$ & 0.227 & - & \\
\hline Marital status, married & $0.84(0.65-1.09)$ & 0.185 & - & \\
\hline Age at onset, higher & $1.00(0.98-1.02)$ & 0.833 & - & \\
\hline Number of depressive episodes, higher & $0.97(0.88-1.07)$ & 0.572 & $0.85(0.78-0.93)$ & $<0.001^{\dagger}$ \\
\hline Duration of present episode, higher & $0.98(0.97-0.99)$ & $0.015^{*}$ & - & \\
\hline Hamilton Depression Rating Scale, higher & $0.99(0.97-1.03)$ & 0.958 & - & \\
\hline Hospital Anxiety \& Depression Scale-anxiety subscale, higher & $0.99(0.95-1.02)$ & 0.440 & $0.99(0.95-1.03)$ & 0.664 \\
\hline Social and Occupational Functional Assessment Scale, higher & $1.03(1.02-1.05)$ & $<0.001^{\dagger}$ & - & \\
\hline Number of stressful life events, higher & $0.95(0.87-1.03)$ & 0.178 & - & \\
\hline Perceived Stress Scale, higher & $1.00(0.98-1.03)$ & 0.726 & $0.98(0.95-1.00)$ & $0.050^{*}$ \\
\hline Connor-Davidson Resilience Scale, higher & $1.00(0.99-1.01)$ & 0.438 & - & \\
\hline Social Support Deficit, higher & $1.01(1.00-1.02)$ & $0.047^{*}$ & - & \\
\hline
\end{tabular}

$\mathrm{OR}$, odds ratio; $\mathrm{Cl}$, confidence interval.

${ }^{*} p<0.05,{ }^{\dagger} p<0.01$.

remission rate at 12 months was $70.4 \%$ (715 of 1,015 patients). The baseline sociodemographic and clinical characteristics of the 12-month patient sample are compared by remission status in Table 1. In unadjusted analyses, remission was associated with fewer previous depressive episodes and lower baseline HADS and self-report Perceived Stress Scale (PSS) scores.

\section{Predictors of Remission}

Predictors of remission during the acute and continuation treatment phases are summarized in Table 2 . In multivariate analyses, the factors that retained a significant association with remission were higher age of onset, shorter-duration present episode, baseline HAMD score and HADS-A and SOFAS scores. In adjusted analyses, the strength of the association between remission and the number of previous depressive episodes remained significant.

\section{DISCUSSION}

This naturalistic study investigated the outcomes of depressive disorders treated by mental health care services in Korea. The study was designed to mimic real-world clinical care rather than a laboratory environment. In total, $43.3 \%$ of patients achieved remission by 12 weeks and $70.4 \%$ achieved remission by 12 months. A shorterduration current depressive episode, high SOFAS score, and good social support were associated with remission during the acute (12-week) treatment phase. Fewer pre- vious depressive episodes and lower perceived stress were associated with remission during the continuation (12-month) treatment phase. The proportion of patients showing acute-phase remission in this study $(43.3 \%)$ was higher than that in the STAR*D Level 1 study (28\%) [3], where the studies were similar in terms of inclusion and exclusion criteria, and duration of treatment. The severity of baseline depression, indexed by the mean HAMD score, was also similar between the studies (21.3 in this study, 21.8 in STAR*D). The variety of antidepressants and use of switching, combination and augmentation strategies might explain the higher remission rate in this study. During the continuation treatment phase, the remission rate in this study $(70.4 \%)$ was slightly higher than that in the STAR*D Level 1 study $(67 \%)$. In the STAR*D study, switching, augmentation, and combination treatment strategies were used more during follow-up than during the acute phase [26]. These findings suggest that flexibility in prescribing, consideration of the characteristics of each individual case, and the availability of more treatment strategies may be beneficial.

During the acute treatment phase, a significant predictor of remission within 12 weeks was a shorter-duration current depressive episode. An 8-week randomized controlled trial (RCT) of duloxetine also found that a shorter-duration current MDD episode predicted remission [27]. A multi-center RCT (with variable treatment duration) showed that a depressive episode length of $<24$ months predicted remission [28]. Chronic depression is related to poor outcomes and treatment resistance [29]. 
Although this study excluded patients with treatment-resistant depression, the duration of the depressive episode was clearly associated with clinical outcome, so can be used as a predictor of remission.

Functioning, assessed using the SOFAS, was also an important predictor of remission during the acute treatment phase. A previous cross-sectional study that also used the SOFAS found that the severity of the current depressive episode and recurrence of depression were associated with the patient's level of functioning [30]. It is well known that depression causes cognitive and psychosocial dysfunction lasting for weeks to years [31]. However, most prior studies only assessed whether depression treatment improved impaired functioning $[32,33]$. The present study suggests that functional assessments could be useful not only in the evaluation of depression treatment, but also as a predictor of treatment outcomes during the acute treatment phase.

Another significant predictor of remission within 12 weeks was good social support, as measured using the Multidimensional Scale of Perceived Social Support. Several previous studies cited social support as a factor affecting the treatment response and outcome [34,35]. It should be noted that social support was evaluated in this study subjectively, i.e., via self-report measures. This data suggest that an individualized approach to improving social support might be helpful in acute depression treatment.

Regarding the continuation treatment phase, the most powerful predictor of remission within 12 months was fewer previous depressive episodes, as also found in a previous study [36]. There is a strong correlation between depressive disorder relapse/recurrence and the number of previous episodes. For individuals who experience frequent relapses, a poor outcome of continuation treatment should be expected, such that a requirement for long-term management of depression is likely.

Perceived stress, as measured by the PSS, predicted remission during continuation treatment. This may be explained by the hypothalamic-pituitary-adrenal axis; excessive or prolonged activation of this axis could lead to a deleterious homeostatic state [37]. Higher stress could promote long-duration depressive episodes.

The strengths of this study included the large sample size, standardized research protocol, and use of well-established scales. As explained above, this study aimed to identify predictors of depression remission during both short- and long-term treatment. The naturalistic study design was another strength; by reflecting real-world clinical situations, the applicability of the findings to the clinical setting was enhanced.

Several limitations of this study should also be acknowledged. First, despite its strengths, the naturalistic study design also has potential limitations. Because the treatment strategy was ultimately decided by individual clinicians rather than according to a predetermined protocol, the outcomes may have been affected by inter-clinician variability. Second, fewer patients underwent treatments involving multiple steps or switching compared to those whose regimens involved augmentation or combination treatment strategies; this may have reduced the statistical power and generalizability of the results. Third, we were unable to compare outcomes by antidepressant type or use of other medications, due to the relatively small numbers of patients in each treatment strategy subgroup. Fourth, follow-up rates were lower in the context of long-term treatment, and patients lost to follow-up were more likely to have had a poor prognosis at baseline. Fifth, the patients were recruited from a single site, which may limit the generalizability of the findings. However, a single-site design is beneficial in terms of the consistency of evaluations and treatments.

Despite its limitations, including the lack of a placebo control group, this study has several important potential implications for clinicians. The relatively high remission rates suggest that individualized treatment, among other clinical factors, might confer benefits during both the short- and long-term treatment phases. Further research focusing on ways to improve the outcomes of groups expected to show high remission rates is needed.

\section{- Conflicts of Interest}

No potential conflict of interest relevant to this article was reported.

\section{- Author Contributions}

Conceptualization: Ha-Yeon Kim and Jae-Min Kim. Data acquisition: Hee-Joon Lee, Min Jhon, and Ju-Wan Kim. Formal analysis: Ha-Yeon Kim. Funding: Jae-Min Kim. Supervision: Hee-Ju Kang, Ju-Yeon Lee, Sung-Wan Kim, and II-Seon Shin. Writing-original draft: Ha-Yeon Kim and Jae-Min Kim. Writing-review \& editing: Hee-Joon Lee, Min Jhon, Ju-Wan Kim, Hee-Ju Kang, Ju-Yeon Lee, 
Sung-Wan Kim, and II-Seon Shin.

\section{ORCID}

Ha-Yeon Kim

Hee-Joon Lee

Min Jhon

Ju-Wan Kim

Hee-Ju Kang

Ju-Yeon Lee

Sung-Wan Kim

Il-Seon Shin

Jae-Min Kim https://orcid.org/0000-0001-5446-2882

https://orcid.org/0000-0001-9611-8238

https://orcid.org/0000-0002-0408-768X

https://orcid.org/0000-0002-9888-1090

https://orcid.org/0000-0002-4784-4820

https://orcid.org/0000-0003-0653-7223

https://orcid.org/0000-0002-6739-2163

https://orcid.org/0000-0001-5370-7649

https://orcid.org/0000-0001-7409-6306

\section{REFERENCES}

1. World Health Organization. Depression [Internet]. Geneva: World Health Organization; 2020 Jan 30 [cited at 2020 Jun 25]. Available from: http://www.who.int/mediacentre/factsheets/fs369/en/.

2. Whiteford HA, Degenhardt L, Rehm J, Baxter AJ, Ferrari AJ, Erskine $\mathrm{HE}$, et al. Global burden of disease attributable to mental and substance use disorders: findings from the Global Burden of Disease Study 2010. Lancet 2013;382:1575-1586.

3. Trivedi MH, Rush AJ, Wisniewski SR, Nierenberg AA, Warden D, Ritz L, et al. Evaluation of outcomes with citalopram for depression using measurement-based care in STAR*D: implications for clinical practice. AmJ Psychiatry 2006; 163:28-40.

4. Dawson MY, Michalak EE, Waraich P, Anderson JE, Lam RW. Is remission of depressive symptoms in primary care a realistic goal? A meta-analysis. BMC Fam Pract 2004;5:19.

5. Iniesta R, Malki K, Maier W, Rietschel M, Mors O, Hauser J, et al. Combining clinical variables to optimize prediction of antidepressant treatment outcomes. J Psychiatr Res 2016;78:94-102.

6. Kupfer DJ, Frank E, Phillips ML. Major depressive disorder: new clinical, neurobiological, and treatment perspectives. Lancet 2012;379:1045-1055.

7. Carter GC, Cantrell RA, Zarotsky V, Haynes VS, Phillips G, Alatorre $\mathrm{Cl}$, et al. Comprehensive review of factors implicated in the heterogeneity of response in depression. Depress Anxiety 2012;29:340-354.

8. Sakado K, Sato T, Uehara T, Sakado M, Someya T. Perceived parenting pattern and response to antidepressants in patients with major depression. J Affect Disord 1999;52:59-66.

9. Saghafi R, Brown C, Butters MA, Cyranowski J, Dew MA, Frank E, et al. Predicting 6-week treatment response to escitalopram pharmacotherapy in late-life major depressive disorder. Int J Geriatr Psychiatry 2007;22:1141-1146.

10. Raskin J, Xu JY, Kajdasz DK. Time to response for duloxetine $60 \mathrm{mg}$ once daily versus placebo in elderly patients with major depressive disorder. Int Psychogeriatr 2008;20:309-327.

11. Khan A, Brodhead AE, Kolts RL, Brown WA. Severity of depressive symptoms and response to antidepressants and pla-

cebo in antidepressant trials. J Psychiatr Res 2005;39:145-150.

12. Cheng IC, Liao SC, Lee MB, Tseng MM. Predictors of treatment response and length of stay for inpatients with major depression. J Formos Med Assoc 2007; 106:903-910.

13. Andreescu C, Lenze EJ, Dew MA, Begley AE, Mulsant BH, Dombrovski AY, et al. Effect of comorbid anxiety on treatment response and relapse risk in late-life depression: controlled study. Br J Psychiatry 2007;190:344-349.

14. Russell JM, Koran LM, Rush J, Hirschfeld RM, Harrison W, Friedman ES, et al. Effect of concurrent anxiety on response to sertraline and imipramine in patients with chronic depression. Depress Anxiety 2001;13:18-27.

15. Kelley ME, Dunlop BW, Nemeroff CB, Lori A, Carrillo-Roa T, Binder $\mathrm{EB}$, et al. Response rate profiles for major depressive disorder: characterizing early response and longitudinal nonresponse. Depress Anxiety 2018;35:992-1000.

16. Olgiati P, Serretti A, Souery D, Dold M, Kasper S, Montgomery $\mathrm{S}$, et al. Early improvement and response to antidepressant medications in adults with major depressive disorder. Metaanalysis and study of a sample with treatment-resistant depression. J Affect Disord 2018;227:777-786.

17. Kang HJ, Kim JW, Kim SY, Kim SW, Shin HY, Shin MG, et al. The MAKE Biomarker discovery for Enhancing anTidepressant Treatment Effect and Response (MAKE BETTER) study: design and methodology. Psychiatry Investig 2018;15:538-545.

18. Sheehan DV, Lecrubier $\mathrm{Y}$, Sheehan $\mathrm{KH}$, Amorim $\mathrm{P}$, Janavs J, Weiller E, et al. The Mini-International Neuropsychiatric Interview (M.I.N.I.): the development and validation of a structured diagnostic psychiatric interview for DSM-IV and ICD-10. J Clin Psychiatry 1998;59 Supp/ 20:22-33; quiz 34-57.

19. Hamilton M. A rating scale for depression. J Neurol Neurosurg Psychiatry 1960;23:56-62.

20. Zigmond AS, Snaith RP. The hospital anxiety and depression scale. Acta Psychiatr Scand 1983;67:361-370.

21. Rabin R, de Charro F. EQ-5D: a measure of health status from the EuroQol Group. Ann Med 2001;33:337-343.

22. Bauer M, Pfennig A, Severus E, Whybrow PC, Angst J, Möller HJ. World Federation of Societies of Biological Psychiatry (WFSBP) guidelines for biological treatment of unipolar depressive disorders, part 1: update 2013 on the acute and continuation treatment of unipolar depressive disorders. World I Biol Psychiatry 2013;14:334-385.

23. Malhi GS, Bassett D, Boyce P, Bryant R, Fitzgerald PB, Fritz K, et al. Royal Australian and New Zealand College of Psychiatrists clinical practice guidelines for mood disorders. Aust N ZJ Psychiatry 2015;49:1087-1206.

24. Kennedy SH, Lam RW, Mclntyre RS, Tourjman SV, Bhat V, Blier P, et al. Canadian Network for Mood and Anxiety Treatments (CANMAT) 2016 clinical guidelines for the management of adults with major depressive disorder: section 3. Pharmacological treatments. Can J Psychiatry 2016;61:540-560.

25. Swift JK, Callahan JL. The impact of client treatment preferences on outcome: a meta-analysis. J Clin Psychol 2009;65: 
368-381.

26. Rush AJ, Trivedi MH, Wisniewski SR, Nierenberg AA, Stewart JW, Warden D, et al. Acute and longer-term outcomes in depressed outpatients requiring one or several treatment steps: a STAR ${ }^{*}$ D report. Am J PSychiatry 2006;163:1905-1917.

27. Nelson JC, Zhang Q, Deberdt W, Marangell LB, Karamustafalioglu O, Lipkovich IA. Predictors of remission with placebo using an integrated study database from patients with major depressive disorder. Curr Med Res Opin 2012;28:325-334.

28. Riedel M, Möller HJ, Obermeier M, Adli M, Bauer M, Kronmüller K, et al. Clinical predictors of response and remission in inpatients with depressive syndromes. J Affect Disord 2011;133:137-149.

29. Zisook S, Johnson GR, Tal I, Hicks P, Chen P, Davis L, et al. General predictors and moderators of depression remission: a VAST-D report. Am J Psychiatry 2019;176:348-357.

30. Rytsälä HJ, Melartin TK, Leskelä US, Sokero TP, LesteläMielonen PS, Isometsä ET. Functional and work disability in major depressive disorder. J Nerv Ment Dis 2005;193:189195.

31. Knight MJ, Baune BT. Cognitive dysfunction in major depres- sive disorder. Curr Opin Psychiatry 2018;31:26-31.

32. Sheehan DV, Nakagome K, Asami Y, Pappadopulos EA, Boucher M. Restoring function in major depressive disorder: a systematic review. J Affect Disord 2017;215:299-313.

33. Culpepper L, Lam RW, McIntyre RS. Cognitive impairment in patients with depression: awareness, assessment, and management. J Clin Psychiatry 2017;78:1383-1394.

34. Bosworth HB, Voils Cl, Potter GG, Steffens DC. The effects of antidepressant medication adherence as well as psychosocial and clinical factors on depression outcome among older adults. Int J Geriatr Psychiatry 2018;23:129-134.

35. Cowan MJ, Freedland KE, Burg MM, Saab PG, Youngblood $\mathrm{ME}$, Cornell CE, et al. Predictors of treatment response for depression and inadequate social support--the ENRICHD randomized clinical trial. Psychother Psychosom 2008;77: 27-37.

36. Johansson O, Lundh LG, Bjärehed J. 12-Month outcome and predictors of recurrence in psychiatric treatment of depression: a retrospective study. Psychiatr Q 2015;86:407-417.

37. Juruena MF. Early-life stress and HPA axis trigger recurrent adulthood depression. Epilepsy Behav 2014;38:148-159. 